\title{
Leveraging Blockchain in Medical Tourism Value Chain
}

\author{
Sreejith Balasubramanian ${ }^{1(\bowtie)}(\mathbb{D})$, Shalini Ajayan $^{2}$ (D), \\ and Cody Morris Paris ${ }^{1}$ \\ 1 Middlesex University Dubai, Dubai, UAE \\ \{s.balasubramanian, c.paris\}@mdx. ac. ae \\ 2 Mohammed bin Rashid School of Government, Dubai, UAE \\ shalini.ajayan@mbrsg.ac.ae
}

\begin{abstract}
There are significant challenges facing the medical tourism industry: privacy and transparency concerns, lack of access to centralized medical records, fraudulent practices, opportunistic behavior of intermediaries, foreign currency risks, and contractual/legal issues. While blockchain technology has immense potential to address the industry's inherent challenges and inefficiencies, the current understanding of blockchain application in medical tourism is fragmented. Through a pragmatic review of the literature, this study explores the blockchain applications and benefits for medical tourists across the stages of the medical tourism value chain, and in the process, proposes a meaningful and managerially relevant blockchain framework for medical tourism. The findings and the proposed novel framework to guide policy interventions and support mechanisms to take advantage of the full opportunities of blockchain in medical tourism.
\end{abstract}

Keywords: Health tourism $\cdot$ Conceptual framework $\cdot$ Blockchain technology

\section{Introduction}

Medical tourism refers to the mobility of individuals to another country in order to receive some form of medical treatment. It has witnessed significant growth over the last two decades, with an estimated 20 million patients crossing borders each year to receive medical treatments [1]. Blockchain or distributed ledger technology appears to be a natural fit for the industry as it offers immutable, transparent, secure, trustworthy, and interoperable solutions [2]. Using blockchain, the healthcare providers could enhance aspects that medical tourists value the most, such a quality, accessibility, affordability, transparency, and security [3]. In addition, blockchain could help overcome the problems and inefficiencies inherent to the medical tourism industry. However, the current literature on blockchain in medical tourism is largely limited and fragmented. Hence, practitioners are mostly unaware of the full potential of blockchain in medical tourism, which in turn could hamper its large-scale acceptability and implementation. This formed the motivation of this study, which aims to develop an enabling 'Blockchain Framework for Medical Tourism' that captures the various blockchain applications and their benefits for patient-tourists across the medical tourism value chain. 


\section{Research Methodology}

A pragmatic approach involving an exploratory review of scattered academic literature and industry sources, including magazines, reports, and news articles from leading consulting firms, governments, and global organizations were undertaken (Fig. 1).

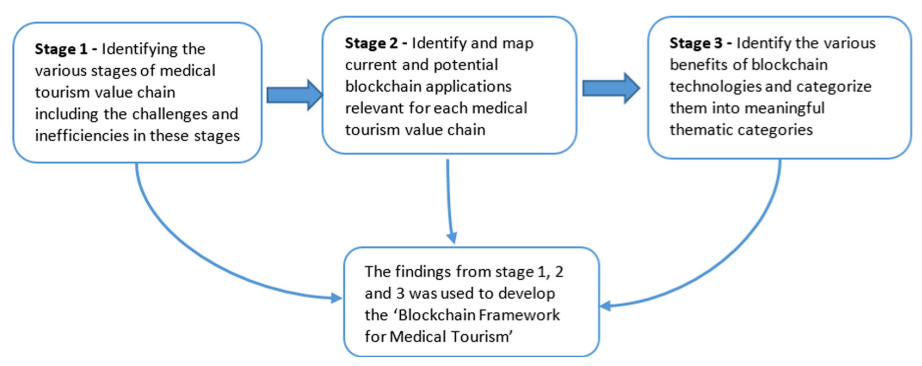

Fig. 1. Research stages

\section{Findings and Discussions}

\subsection{Pre-procedural Phase}

In this phase, the tourist must take several decisions, including the choice of medical travel facilitator, medical providers like hospitals or doctors, and the destination country [1]. In most cases, patients may not have the opportunity to visit the destination country and healthcare provider before making the final treatment decision. Hence, they rely heavily on online search information, reviews and ratings. Unfortunately, the inability to distinguish between genuine and fake reviews and ratings is a critical issue for medical tourists. The blockchain platforms ensure authentic customer reviews from fake ones with traceable identities. The immutability nature of blockchain ensures that any review posted in the blockchain cannot be deleted, and updates are only possible with a traceable history. Further, blockchain enables the verification of qualifications and credentials of healthcare providers by linking with the certification bodies [3]. The other concern is the medical tourists' heavy reliance on intermediaries such as agents to organize the trip [1]. Often, such intermediaries exhibit opportunistic behavior, including fraudulent practices that may adversely affect patients' health and well-being [3]. The peer-to-peer nature of the blockchain network enables potential medical tourists to engage in direct, interactive communication with the healthcare service provider [3]. This disintermediation shifts the balance of power from a healthcare provider (institution-centric) to medical tourists (patient-centric). Disintermediation also minimizes the privacy and security concerns, including data theft, identity theft, and credit card theft that patients may have about sharing their sensitive medical history and financial details with travel agencies or other intermediaries [4, 5]. This is because blockchain is a 'privacy-by-design solution [5] and will give data access only to authorized actors after verification of the identity, such as by using a digital signature or 
by means of a certificate [6]. It also provides more control and ownership for patients on the personal data they share with service providers [5]. The other benefit of blockchain is that it provides a digital paper-free environment and hence eliminates the need for manual or paper-based transactions, which is prone to human errors, and double bookings. Moreover, medical tourists no longer need to carry medical records during travel since the data stored in the blockchain can be accessed from anywhere. Finally, blockchain-enabled digital payment platforms facilitate secure, faster, and direct payments by cryptocurrencies, decreasing the hassles associated with bank intermediation, currency fluctuations, and transaction delays [4] (Fig. 2).

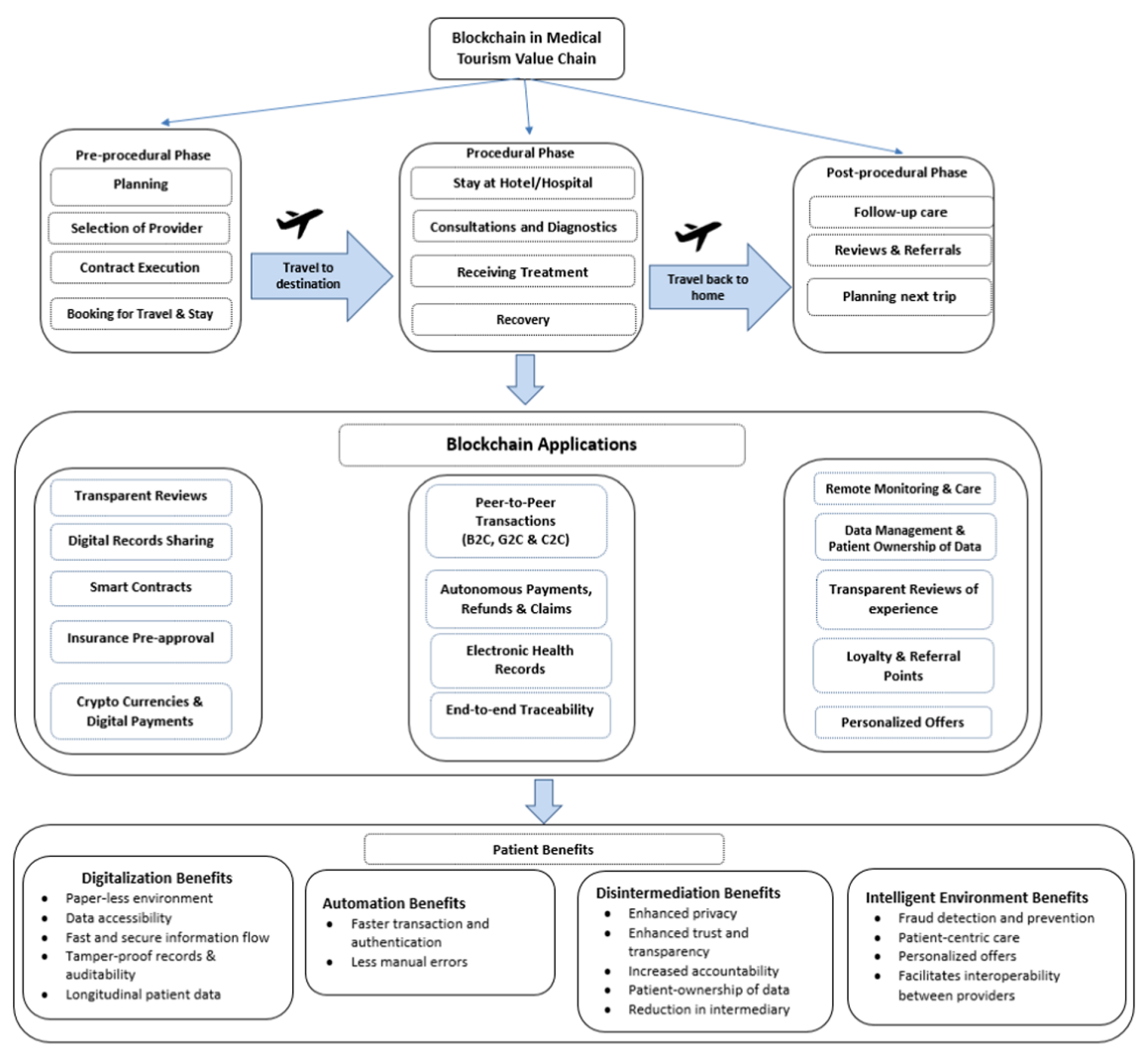

Fig. 2. Blockchain framework for medical tourism

\subsection{Procedural Phase}

In this phase, the patient arrives in the destination country, visits the hospital, undertakes required tests and consultations, and undergoes treatment or procedure. This phase also includes the post-operative care segment when the tourist is still in the destination country. This includes follow-up doctors' visits, additional procedures if required, recuperation in a medical institution or hotels/resorts, medical supplies, 
meals, and relaxation package $[1,7]$. Ideally, the healthcare provider requires access to medical tourists' past health records to enable them to make better choices while providing the treatment. Unfortunately, in most cases, the patients may not have a medical history with them and may not fully recall all the treatments or medications they had taken in the past. The patient electronic health records (EHR) build on a blockchain platform enables tamper-free medical patient history data. It hence eliminates the need for redundant diagnostic tests and consultations for the patient. Also, access to reliable patient data is critical in an emergency during the procedure or during their stay in the destination country [8]. In addition, blockchain facilitates linking family health data with patient data to understand patterns and vulnerabilities in their family health histories, enabling better diagnosis and treatment [2].

The other problem facing medical tourists is the counterfeit, fake, substandard, or degraded drugs and medical supplies [9]. Blockchain solutions enable end-to-end supply chain traceability of medical products from its origin until it reaches the end customer [2] allowing the tourists to determine whether the product is authentic and reliable. Further, for medical tourists seeking new or experimental treatment, detailed information regarding the clinical trials stored in the blockchain increases patient trust and confidence in the treatment [10]. The other concern for medical tourists, especially in countries with weak laws, is the relatively fewer options to fight for their rights in case of fraud or are subject to medical malpractice. Blockchain can address these concerns through smart contracts, which are self-executing and self-enforcing in nature with predefined rules, procedures, and penalties [5]. It can automate a range of business transactions between tourists and service providers without the need for intermediaries and human intervention from a legal perspective [11]. For example, smart contracts can instantly and automatically process medical insurance claims after it detects the completion of treatment, eliminating the need for cumbersome paperwork [11].

\subsection{Post-procedural Phase}

In this phase, the patient leaves the destination country for the home country after recovery but will continue to receive remote treatment, monitoring, and care from the destination country or a different provider in the home country [1,7]. Blockchain can facilitate remote patient care from the destination country [2]. Also, the patients will have tamper-free records of the procedures they underwent and the medications they received, and contact information of the health care professionals who treated the patient in the destination country. The interoperable blockchain environment enables patients, especially those who need extensive follow-up care or for those who develop complications when they return home, to switch to a local healthcare provider [8]. Several blockchain-based platforms provide rewards for medical tourists for transparent sharing of their experience in the form of ratings, reviews, or blogs [12]. All entries are signed with a unique private key which confirms that a specific review comes from a particular user. As a result, reviews are trustworthy since users would be unable to create duplicate reviews with the same identity or manipulate reviews because of the immutability feature of blockchain. Further, medical tourists are rewarded for sharing or authorizing their medical data with service providers in exchange for tokens as 
rewards. Also, they could receive tokens for referring other patients to the destination country or provider [12]. Finally, tourists may receive personalized recommendations, offers, and discounts for their next trip based on the shared data.

\section{Conclusion}

The study provides a systemic overview of the full potential of blockchain applications and their benefits for medical tourism. The study is timely given that the medical tourism industry is trying to recover from the COVID-19 pandemic and that blockchain would help support the recovery process. However, the study has some limitations. Although the framework was developed from an extensive review, it may not cover every blockchain application in medical tourism. Moreover, the framework is not empirically tested in a real-world setting. Despite these limitations, the findings and the framework are useful for practitioners and policymakers looking to take advantage of this technology. Also, researchers could adapt and apply the framework in their respective contexts.

\section{References}

1. Parekh J, Jaffer A, Bhanushali U, Shukla S (2020) Disintermediation in medical tourism through blockchain technology: an analysis using value-focused thinking approach. Inf Technol Tourism 23(1):69-96. https://doi.org/10.1007/s40558-020-00180-4

2. Balasubramanian S, Shukla V, Sethi JS, Islam N, Saloum R (2021) A readiness assessment framework for blockchain adoption: a healthcare case study. Technol Forecast Soc Chang 165(120536):1-16

3. Rejeb A, Keogh JG, Treiblmaier H (2019). The impact of blockchain on medical tourism. In Workshop on E-Business, pp 29-40. Springer, Cham. https://doi.org/10.1007/978-3-03067781-7_4

4. Çapar H (2020) Using cryptocurrencies and transactions in medical tourism. J Econ Admine Sci (Online First)

5. Tyan I, Yagüe MI, Guevara-Plaza A (2020) Blockchain technology for smart tourism destinations. Sustainability 12(22):9715, 1-11

6. Baralla G, Pinna A, Tonelli R, Marchesi M, Ibba S (2021) Ensuring transparency and traceability of food local products: a blockchain application to a smart tourism region. Concurr Comput Pract Exp 33(1):e5857

7. Bürchler K (2020) White paper-a research contribution: international patient journey mapdefining and mapping the patient journey of medical tourists seeking state-of-the-art treatment outside their home country. https://www.sip.ch/international-patient-journey-map/. Accessed 30 Aug 2021

8. Pilkington M (2020) The relation between tokens and blockchain networks: the case of medical tourism in the Republic of Moldova. J British Blockchain Assoc 4(1):1-11

9. Green MD (2020) Perspectives: avoiding poorly regulated medicines and medical products during travel. https://wwwnc.cdc.gov/travel/yellowbook/2020/. Accessed 29 Aug 2021

10. Medical Tourism Magazine (2018) Blockchain technology: a game changer in medical tourism. https://www.magazine.medicaltourism.com/article/blockchain-technology-gamechanger-medical-tourism. Accessed 02 Jun 2021 
11. Shen Y, Bai G (2020) Research on application of blockchain in internationalization of China's medical tourism industry. In 2020 international signal processing, communications and engineering management conference (ISPCEM), pp 63-67. IEEE

12. Nam K, Dutt CS, Chathoth P, Khan MS (2021) Blockchain technology for smart city and smart tourism: latest trends and challenges. Asia Pacific J Tourism Res 26(4):454-468

Open Access This chapter is licensed under the terms of the Creative Commons Attribution 4.0 International License (http://creativecommons.org/licenses/by/4.0/), which permits use, sharing, adaptation, distribution and reproduction in any medium or format, as long as you give appropriate credit to the original author(s) and the source, provide a link to the Creative Commons license and indicate if changes were made.

The images or other third party material in this chapter are included in the chapter's Creative Commons license, unless indicated otherwise in a credit line to the material. If material is not included in the chapter's Creative Commons license and your intended use is not permitted by statutory regulation or exceeds the permitted use, you will need to obtain permission directly from the copyright holder. 